\title{
A micro-scale investigation of the adsorption of collectors on bastnaesite
}

\author{
Jinhong Zhang*, Dongbo An \\ Department of Mining and Geological Engineering \\ The University of Arizona \\ 1235 E. James E. Rogers Way, Tucson, AZ USA 85721 \\ and
}

James Withers

ATS-MER, LLC, Tucson, AZ USA

*Correspondence: jhzhang @email.arizona.edu; Tel.: +1-520-626-9656

\begin{abstract}
A micro-scale investigation was carried out by applying an AFM (atomic force microscope) to study in situ the adsorption of various collectors, i.e., oleic acid, octanohydroxamic acid (HA), and salicylhydroxamic acid (SHA), on bastnaesite in aqueous solutions. The obtained AFM images show that the surface morphology of bastnaesite changes greatly after it contacts the solutions of the collectors, suggesting that all these collectors can effectively adsorb on bastnaesite. Increasing temperature can help increase the adsorption of oleic acid on bastnaesite. ATR-FTIR (attenuated total reflectance Fourier transform infrared) results also show that all these collectors adsorb strongly on bastnaesite with a strong absorbance spectra being detected, which confirms with the results obtained with AFM imaging analysis. In general, hydroxamic acid collector (HA and SHA) adsorbs on bastnaesite mainly in the form of insoluble metal hydroxamate. This specific adsorption mechanism explains that a high selectivity with a moderate collectivity will be achieved with a hydroxamic acid collector for the flotation of bastnaesite.
\end{abstract}

Keywords: bastnaesite, collector, hydroxamic acid, AFM, FTIR 


\section{INTRODUCTION}

Rare earth metals, such as La and Se, which are very important to modern industry, are generally extracted from numerous rare earth minerals. In practice, however, the actual extraction of rare earth minerals is mainly from bastnaesite, monazite, and xenotime. The Mountain Pass mine is one of the largest rare earth mine in the world, at which the main rare earth mineral is bastnaesite. In the past years, froth flotation has been applied to the beneficiation of Mountain Pass ore. In practice, the rare earth ore is usually crushed, milled and further separated from calcite, barite and other gangue minerals by froth flotation, in which the rare earth oxide-bearing minerals stick to aerated bubbles in the pulp and float to the surface, leaving the gangue at the bottom of the flotation cell and disposed of as tailings[1].

In spite of the fact that froth flotation has been applied to treat the bastnaesite ore at the Mountain Pass mine, the rare earth oxide (REO) recovery is still low[2], especially compared to the one obtained with sulfide flotation. For example, the typical recovery obtained at the Mountain Pass mine was only about $70 \%$. This may be due to the low selectivity of the collector (oleic acid). In addition, to enhance the flotation selectivity, the pulp in the mine circuit has to be heated up to 70 to $90^{\circ} \mathrm{C}$, and it involves a lot of energy consumption. Last but not the least, a lot of depressants have to be added to improve the selectivity of flotation process. Therefore, it is critical to re-examine the existing flotation process at the Mountain Pass mine and seek any chance of improvement[2].

In flotation practice, collectors are added into the pulp in flotation cells to selectively adsorb onto the target mineral and render its surface with high hydrophobicity, which is generally beneficial for a strong mineralbubble attachment and thus a high flotation recovery. The low selectivity of oleic acid is believed to be the reason for the low efficiency of Mountain Pass mine flotation. Thus, the search of novel collector for bastnaesite is called for to improve the flotation performance [2-4].

In the present study, in order to explore the underlying mechanism of the flotation process such as the collectors' adsorption mechanism on bastnaesite surface, AFM and ATR-FTIR will be applied to study the adsorption behavior of collectors on bastnaesite surface. The information is of great importance for the development of new flotation scheme of bastnaesite.

\section{Experimental}

\subsection{Materials}

High grade bastnaesite ore samples obtained from the Mountain Pass mine were provided by Molycorp Inc., CA. Samples were cut, and finely polished to expose fresh surfaces, then cleaned by rinsing thoroughly with ethanol and deionized water, finally blown to dry by nitrogen gas for AFM and FTIR measurements. The deionized water as used in all the experimental work has a resistivity of $18.2 \mathrm{M} \Omega \cdot \mathrm{cm}$ at $25^{\circ} \mathrm{C}$, and a surface tension of DI water at $72.5 \mathrm{mN} / \mathrm{m}$ at $25^{\circ} \mathrm{C}$. Oleic acid (>99\%) and Sodium octanohydroxamate hydrate $(>98 \%)$ were obtained from Tokyo Chemical Industry America (Portland, OR). Salicylhydroxamic acid $(>99 \%)$ was obtained from Alfa Aesar (Haverhill, MA). All the chemicals were used as received without further purification. Solutions were freshly prepared each time right before the test of surface characterization.

\subsection{AFM imaging analysis}

Surface image measurements were carried out in contact mode by a Digital Instrument Nanoscope IIId AFM at room temperature $\left(25 \pm 1^{\circ} \mathrm{C}\right)$. Silicon nitride NP cantilevers with nominal spring constant of 0.12 $0.58 \mathrm{~N} / \mathrm{m}$ were obtained from Veeco, CA. For the study of mineral surface in water, surface image measurements were conducted right after the nanopure water was injected into an AFM fluid cell. After the surface image data was collected, a $10 \mathrm{ml}$ solution of a specific concentration was flushed through the liquid cell, and the AFM measurement was commenced after the exposure of the mineral plate to the solution for a specific time. No image modification other than flattened were conducted. When the study of temperature 
effect is involved, an AFM high-temperature heater/cooler was installed. The variance in temperature was within $\pm 1{ }^{\circ} \mathrm{C}$.

\subsection{ATR-FTIR analysis}

A Nicolet 6700 FTIR spectrometer equipped with the Smart iTR accessory was used to collect mid-infrared spectra. The system was equipped with a DTGS KBr detector and a diamond ATR crystal with an angle of incidence of $45^{\circ}$. Fresh mineral surface was pressed and fastened against the ATR crystal to collect background spectra. Sample spectra was collected after soaking in collector solutions of different concentrations and temperatures for specific time. The intensities in the FTIR spectra were shown in a relative absorbance under the same scale for the sake of complexity of reflection spectroscopy. No further treatment was made towards spectra except baseline correction.

\section{Results and discussion}

\subsection{AFM imaging analysis}

The AFM imaging technique has been widely applied in the surface characterization of various materials. It was employed in this study to obtain the morphology of bastnaesite surfaces. By comparing the obtained images before and after the addition of chemicals, it will be known that not only the change of morphology, but also possibly the reaction products on solids[5, 6].

Figure 1 shows the AFM images of bastnaesite soaking in water for 30 mins. Fig. 1A is the $5 \mu \mathrm{m} \times 5 \mu \mathrm{m}$ height image with a data scale of $5 \mathrm{~nm}$. It can be seen from the image that the bastnaesite surface as studied is quite smooth, with only some scratch lines due to surface polishing being observed. The obtained images confirmed that the mineral surface was smooth enough for an AFM surface image analysis. Usually a highly smooth surface is beneficial for the study of chemicals on minerals because the influence from the background surface is negligible. Fig. 1B is the 3-D image of Fig.1A. Fig. 1C is the section analysis, showing a typical line roughness is only $0.56 \mathrm{~nm}$ as measured on the white line. Fig. 1D is the deflection image with a data scale of $5 \mathrm{~nm}$. Fig. 1 shows that the bastnaesite surface is stable when it is soaked in water for 30 mins with no noticeable change in surface morphology being detected within the time frame. The same conclusion was also better supported by Figure 3, which is shown in a following section.

Figure 2 shows the AFM images of bastnaesite soaked in oleic acid solutions. Fig. 2A is the AFM image of bare bastnaesite surface soaked in water, which is obtained before the injection of oleic acid solution. Fig. $2 \mathrm{~B}$ is the AFM image obtained after the sample is soaked in $0.02 \mathrm{~g} / \mathrm{L}$ oleic acid for $20 \mathrm{mins}$. By comparing Fig. 2A with Fig. 2B, one can see that the surface morphology of rare earth has changed a lot with the scratches being covered by some adsorbate and becoming much 'blur'.

Figure 3 shows the AFM images of bastnaesite soaked in oleic acid solutions at different temperatures. Fig. $3 \mathrm{~A}$, the image obtained in air, shows that the polished mineral surface is quite smooth with only some scratches being observed on mineral surface due to surface polishing. Fig. 3B is the AFM image of bare rare earth surface soaked in water for 20 mins. By comparing Fig. 3A and Fig. 3B, one can see that the mineral surface remains the same with almost no change in surface morphology being observed. Fig. $3 \mathrm{C}$ is the AFM image obtained after the sample has been soaked in $0.02 \mathrm{~g} / \mathrm{L}$ oleic acid for 20 mins at $60{ }^{\circ} \mathrm{C}$ and further cooled down to room temperature. Fig. $3 \mathrm{C}$ clearly shows that there are many patches appearing on bastnaesite surface. The patches are very likely of an 'oily' substance, because the patches, in general, have smooth and round boundaries, of which the morphology is totally different from that of precipitates. Fig. $3 \mathrm{D}$ is a $5 \mu \mathrm{m} \times 5 \mu \mathrm{m}$ image to show the smooth and round boundaries of the patches. Fig. 3E is the $5 \mu \mathrm{m} \times$ $5 \mu \mathrm{m}$ image obtained after a very large scan force is applied during scanning. There are no patches being observed on mineral surface anymore and the image is very similar to Fig. 3B, as obtained in water only. Further, the bastnaesite surface is scanned again with a much small force and the $10 \mu \mathrm{m} \times 10 \mu \mathrm{m}$ image is shown as Fig. 3F. A blank 'window' is clearly shown in the center of the image because of the removal of 
the adsorbate from mineral surface under the applied large scan force. That is, the 'window' in the center is the bare rare earth surface and the surrounding area is the mineral surface covered by the adsorbed oleic acid. To confirm this, after the AFM probe was intentionally moved to another position above the mineral, the surface is scanned again following the same strategy, and the results are shown as Fig. 3G and Fig. 3H. The same finding is obtained as the one shown in Fig. 3C and F.

Figure 4 shows the AFM images of bastnaesite soaked in octanohydroxamic acid solutions. Fig. 4A is the AFM image of bare rare earth surface soaked in water. Fig. 4B is the image obtained after the sample has been soaked in $0.02 \mathrm{~g} / \mathrm{L}$ octanohydroxamic acid for 10 mins. By comparing Fig. 4A and Fig. 4B, one can clearly see that some adsorbate appears on rare earth surface. Fig. 4C, 4D and 4E are respectively the images obtained with a ten minutes interval after Fig. 4B. The mineral surface is fully covered by a lot of adsorbate. In order to clarify this point, a $5 \mu \mathrm{m} \times 5 \mu \mathrm{m}$ area is scanned for one time with a much larger scan force being applied to remove the adsorbate. Further, the surface was imaged again in a $10 \mu \mathrm{m} \times 10 \mu \mathrm{m}$ area and the result was shown as Fig. 4F. A blank 'window' is shown in the center of the image because of the removal of the adsorbate from mineral surface under the applied large scan force. That is, the 'window' in the center shows bare rare earth surface and the surrounding area is the mineral surface covered by adsorbate. Fig.4 shows alkyl hydroxamic acid adsorbs with preference on bastnaesite mainly in a form different from oily substance as shown by Fig. 3, with the surface of rare earth mineral fully covered. In addition, the adsorption of $\mathrm{OA}$ on bastnaesite increases with increasing the adsorption time during the first 20 mins contact time, as shown by Fig. 4B and Fig. 4C.

Figure 5 shows the AFM images of bastnaesite soaked in salicylhydroxamic acid solutions. Fig. 5A is the AFM image of bare bastnaesite surface soaked in water. Fig. 5B is the image obtained after the sample has been soaked in $0.02 \mathrm{~g} / \mathrm{L}$ SHA for 10 mins. By comparing Fig. 5A and Fig. 5B, one can clearly see that some adsorbate appears on rare earth surface. Fig. $5 \mathrm{C}$ is the image obtained after the sample has been soaked in $0.2 \mathrm{~g} / \mathrm{L}$ SHA for 20 mins. By comparing Fig. 5C and Fig. 5A and Fig. 5B, one can see that there are a lot of adsorbate appearing on rare earth surface. Similarly, in order to verify the adsorption, a $5 \mu \mathrm{m} \times 5 \mu \mathrm{m}$ area is scanned for once with a much larger scan force being applied to remove the adsorbate. Further, the surface was imaged again in a $10 \mu \mathrm{m} \times 10 \mu \mathrm{m}$ area and the result was shown as Fig. 5D. A blank 'window' is also shown in the center of the image because of the removal of the adsorbate from mineral surface under the applied large scan force. That is, the 'window' in the center is the bare rare earth surface and the surrounding area is the mineral surface covered by the adsorbed salicylhydroxamic acid. Fig. 5 shows salicylhydroxamic acid adsorbs with preference on rare earth. Increasing the chemical's concentration is beneficial for a complete coverage of the adsorbate on bastnaesite surface.

\subsection{FTIR analysis}

Figure 6 is the FTIR spectra of a clean and smooth bastnaesite surface. As a fluoro-carbonate mineral, the infrared spectra of bastnaesite is no doubt displaying characteristic peaks of carbonate mineral. It is typically considered that carbonate structure is identified in infrared spectra by 4 sets of vibration peaks between $1500 \mathrm{~cm}^{-1}$ and $700 \mathrm{~cm}^{-1}$ [7]. In the spectra of bastnaesite, the peaks are corresponding to the antisymmetric stretching vibration of $\mathrm{CO}_{3}{ }^{2-}$ at $1447 \mathrm{~cm}^{-1}$; symmetric stretching vibration of $\mathrm{CO}_{3}{ }^{2-}$ at 1086 $\mathrm{cm}^{-1}$; out-of-plane bending vibration $\mathrm{CO}_{3}{ }^{2-}$ at $868 \mathrm{~cm}^{-1}$; in-plane bending vibration $\mathrm{CO}_{3}{ }^{2-}$ at 750 and 727 $\mathrm{cm}^{-1}[8,9]$. However, as can be told from Fig. 6 , the number of vibration peaks related to $\mathrm{CO}_{3}{ }^{2-}$ is different from typical carbonate spectra, also the wavenumbers of peaks vary. Fig. 6 displays 6 peaks in the carbonate range, namely a strong and wide peak at $1339 \mathrm{~cm}^{-1}$ with a strong peak at $1477 \mathrm{~cm}^{-1}$ on its shoulder; one strong peak at $1085 \mathrm{~cm}^{-1}$ and another strong peak at $861 \mathrm{~cm}^{-1}$, a doublet at $746 \mathrm{~cm}^{-1}$ and $717 \mathrm{~cm}^{-1}$.

Fig. 7 showed the FTIR spectra of pure chemicals. The spectra are collected $4000 \mathrm{~cm}^{-1}-600 \mathrm{~cm}^{-1}$. The oleic acid is measured in liquid form, while the other 2 chemicals are measured in solid powder state, of which the patterns of spectra between $1800 \mathrm{~cm}^{-1}$ and $600 \mathrm{~cm}^{-1}$ are highly similar, since their major function groups are all hydroxamic acids. The standard infrared spectra of the reagents above could be found in the infrared data base. The spectra in Fig. 7 had little deviation from standard references, owing to the high purity (>98\%) 
of reagents applied. For example, the spectra of oleic acid had strong peaks at $2922 \mathrm{~cm}^{-1}$ and $2853 \mathrm{~cm}^{-1}$, representing the $\mathrm{C}-\mathrm{H}$ vibration in the hydrocarbon chain, also the $\mathrm{C}=\mathrm{O}$ vibration peak can be observed at $1708 \mathrm{~cm}^{-1}$. The results as shown in Fig. 7 confirms the reliability of the three reagents as used in present study and the spectra can work as references in a further infrared study on the adsorption of chemicals on bastnaesite.

Fig. 8 shows the FTIR spectra of bastnaesite surface after it respectively contacts with $0.2 \mathrm{~g} / \mathrm{L} \mathrm{OA}, 0.2 \mathrm{~g} / \mathrm{L}$ HA and $0.4 \mathrm{~g} / \mathrm{L}$ SHA. The bastnaesite background $\left(1500-700 \mathrm{~cm}^{-1}\right)$ is also included in the spectra. In Fig. $8 \mathrm{~A}$, the infrared spectra showed a strong doublet at $2922 \mathrm{~cm}^{-1}$ and $2853 \mathrm{~cm}^{-1}$, a strong peak at $1715 \mathrm{~cm}^{-1}$ and a medium peak at $1541 \mathrm{~cm}^{-1}$. The strong doublets at $2922 \mathrm{~cm}^{-1}$ and $2853 \mathrm{~cm}^{-1}$ represented the C-H stretching vibration of aliphatic group in the hydrocarbon chain of oleic acid. One previous study is also focused on the absorbance peak at $3000 \mathrm{~cm}^{-1}$ to $3010 \mathrm{~cm}^{-1}$, indicating the existence of $=\mathrm{CH}$ [8], which existed in the middle of carbon chain and thus made it an unsaturated carboxylic acid. The peak at 1715 $\mathrm{cm}^{-1}$ can be also observed in the oleic acid reference spectra, which is the result of $\mathrm{C}=\mathrm{O}$ vibration of carboxylic acid. The medium strong peak at $1541 \mathrm{~cm}^{-1}$ is a new peak generated by the adsorption reaction, and does not exist in reference spectra of oleic acid. In fact, the major functioning components in basic solution is oleate ions, which is characterized by $\mathrm{C}-\mathrm{O}$ vibration at $1560 \mathrm{~cm}^{-1}$. The adsorbed oleate on semisoluble mineral surface has been well studied [11]. The peaks around $1560 \mathrm{~cm}^{-1}$ are associated with asymmetric stretching vibration of C-O. The symmetric stretching vibration of $\mathrm{C}-\mathrm{O}$ should be observed between $1450 \mathrm{~cm}^{-1}$ to $1407 \mathrm{~cm}^{-1}$. Similar infrared spectra of rare earth carboxylates are also obtained by Pavez et al. [12], whose results showed slightly higher wavenumbers at $1585 \mathrm{~cm}^{-1}$ and $1466 \mathrm{~cm}^{-1}$. He et al. [13] reported peak at $1564 \mathrm{~cm}^{-1}$ as the asymmetric stretching vibration of $\mathrm{C}-\mathrm{O}$. The variance of $\mathrm{C}-\mathrm{O}$ peak can be possibly explained by the different resources of oleate, either from oleic acid or sodium oleate. It is in good agreement $[9,12]$ that the significant existence of $\mathrm{C}=\mathrm{O}$ vibration suggested the presence of physically adsorbed oleate on bastnaesite, and the shifting C-O vibration from $1560 \mathrm{~cm}^{-1}$ to $1541 \mathrm{~cm}^{-1}$ indicated the presence of chemisorbed oleate.

In Fig. 8B the infrared spectra showed similar doublets at $2922 \mathrm{~cm}^{-1}$ and $2853 \mathrm{~cm}^{-1}$ with those of Fig. 8A. This is because that HA is also consisting of hydrocarbon chain. However, the relative absorbance responding to the aliphatic group in the carbon chain are much lower than that of Fig. 8A, which could be explained plausibly by the difference of chain length $\left(\mathrm{C}_{18}\right.$ for oleic acid and $\mathrm{C}_{8}$ for $\left.\mathrm{HA}\right)$. Another significant characteristic peak is observed at $1646 \mathrm{~cm}^{-1}$, which is due to the shifting of the characteristic $\mathrm{C}=\mathrm{O}$ vibration peak at $1635 \mathrm{~cm}^{-1}$ as shown in Fig. 7B [14]. The shifting behavior of carbonyl peak suggests a chemisorption of HA on bastnaesite.

Fig. 8C shows the FTIR spectra of bastnaesite after it contacts SHA solution for 15 minutes, which shows that the interference of bastnaesite background completely disappears and the characteristic peaks between $1500 \mathrm{~cm}^{-1}$ to $700 \mathrm{~cm}^{-1}$ can be observed together with peaks between $4000 \mathrm{~cm}^{-1}$ and $1500 \mathrm{~cm}^{-1}$. The characteristic peaks in the spectra include a strong and wide peak at $3300 \mathrm{~cm}^{-1}$, a very strong peak at 1640 $\mathrm{cm}^{-1}$, a shoulder-like peak at $1560 \mathrm{~cm}^{-1}$ and two medium strong peaks at $1454 \mathrm{~cm}^{-1}$ and $890 \mathrm{~cm}^{-1}$.

The strong and wide peak around $3300 \mathrm{~cm}^{-1}$ is the reflection of hydrogen bond vibration in the polar group of hydroxamic acid. The strong peak at $1640 \mathrm{~cm}^{-1}$ responds to the vibration of $\mathrm{C}=\mathrm{O}$ bond (amide I) as discussed above. Similar peak is obtained at $1639 \mathrm{~cm}^{-1}$ by Wang et al. [9]. The vibration of C-N-H (amide II) can be reflected in 2 forms: the trans and the cis. The trans C-N-H vibration is observed between 1570$1510 \mathrm{~cm}^{-1}$; whereas the cis C-N-H vibration is confirmed at 1490-1440 $\mathrm{cm}^{-1}$ [14]. Thus, the peaks observed $1560 \mathrm{~cm}^{-1}$ and $1454 \mathrm{~cm}^{-1}$ are considered as the respective response of trans and cis C-N-H vibration. The medium strong peak at $890 \mathrm{~cm}^{-1}$ is the result of $\mathrm{N}-\mathrm{O}$ stretching vibration.

\section{Conclusions}

AFM imaging analysis and FTIR analysis was applied for the study of three collectors i.e., OA, HA and SHA, on bastnaesite. AFM images showed that all the three collectors adsorb on bastnaesite. The adsorbate of OA on bastnaesite is mainly detected in the form of an oily droplets/film. The increasing solution 
temperature increased the adsorption of OA on mineral surface. HA and SHA adsorb on bastnaesite mainly in the form of insoluble metal salts. Increasing chemical's concentration and contact time increases the amount of adsorbate on mineral surface. FTIR study confirms the adsorption of the three chemicals on bastnaesite. The analysis of FTIR spectra shows that the former adsorbs in the forms of both physical and chemical adsorptions; while chemical adsorption is applicable for the latter two.

\section{Acknowledgements}

The financial support from a DoD Office of Navy Research grant with the contract number N00014-15-C0165 for this study is greatly appreciated. J. Zhang is grateful to Freeport-McMoRan Copper \& Gold, Inc. for sponsoring the Freeport McMoRan Copper and Gold Chair in Mineral Processing in the MGE department at the University of Arizona.

Conflict of Interest: On behalf of all authors, the corresponding author states that there is no conflict of interest.

\section{References}

[1] Bulatovic, S. M., 2010, Flotation of REO minerals, Handbook of Flotation Reagents, Elsevier Science. pp. 151-173.

[2] Anderson, C. D., 2015, Improved Understanding of Rare Earth Surface Chemistry and Its Application to Froth Flotation. Doctoral Dissertation. CSM.

[3] Cao, Y., Cao, Z., Li J., Qu, Q., Wang, J., 2013, Current Study Situation and Development on Flotation of Rare Earth in Bayan Obo Mine. M\&PEqt., Vol.41, No.1. pp. 93-96.

[4] Hadzi, D., PrevorSek, D., 1957. Infrared Absorption Bands Associated with the NH group 1: Hydroxamic Acids and Derivatives. Spectrochimica Acta, Vol.10, No.1. pp. 38-51.

[5] Zhang, J., Zhang, W., The adsorption of collectors on chalcopyrite surface studied by an AFM, in Separation Technologies, Young, C., and Luttrell, G. Ed., SME, 2012, ISBN:978-0-87335-339-7, p6573.

[6] Zhang, J., Zhang, W., An Atomic Force Microscopy Study of the Adsorption of Collectors on Chalcopyrite, in Microscopy: Advances in scientific research and education, A. Méndez-Vilas, Ed., Formatex Research Center, 2014, Vol. 2 ISBN: 978-84-942134-4-1, p 967-973.

[7] Socrates, G. (2001). Infrared and Raman Characteristic Group Wave Numbers. John Wiley and sons, New York.

[8] Xue, L. H.,Yuan, R. (2004). Study on Vibrational Spectra of Rare-earth Fluoro-carbonate Minerals in China. Chinese Journal of Light Scattering, Vol. 16, No.3. pp. 229-233.

[9] Wang, C., Qiu, X., Hu, Z., Tong, X., 2013, Study on the Flotation Mechanism of Bastnaesite by Sodium Oleate. Chinese Rare Earths, Vol 34, No. 6. pp. 24-30.

[10]Hu, J.S., Misra, M., Miller, J.D., 1986. Characterization of Adsorbed Oleate Species at the Fluorite Surface by FT-IR Spectroscopy. IJMP, Vol.18, No.1-2. pp. 73-84.

[11] Young C.A., Miller J.D., 2000, Effect of Temperature on Oleate Adsorption at a Calcite Surface: an FT-NIR/IRS Study and Review, IJMP, Vol.58, No.1. pp. 331-350.

[12] Pavez, O., Brandao, P., Peres, A., 1996, Adsorption of Oleate and Octyl-hydroxamate on to Rare-Earths Minerals. Minerals Engineering, Vol.9, No.3. pp. 357-366.

[13]He, X., Rao, J., Luo, C., Chen, Z., Liu, C., Zhang, J., 2016. Flotation Mechanism of Modified Alkyl Hydroxamic Acid on Bastnaesite. JCSRE, Vol.34, No.2. pp. 244-251.

[14] Higgins, F. S., Magliocco, L. G., Colthup, N. B., 2006. Infrared and Raman Spectroscopy Study of Alkyl Hydroxamic Acid and Alkyl Hydroxamate Isomers. Applied Spectroscopy, Vol.60, No.3. pp. 279-287. 


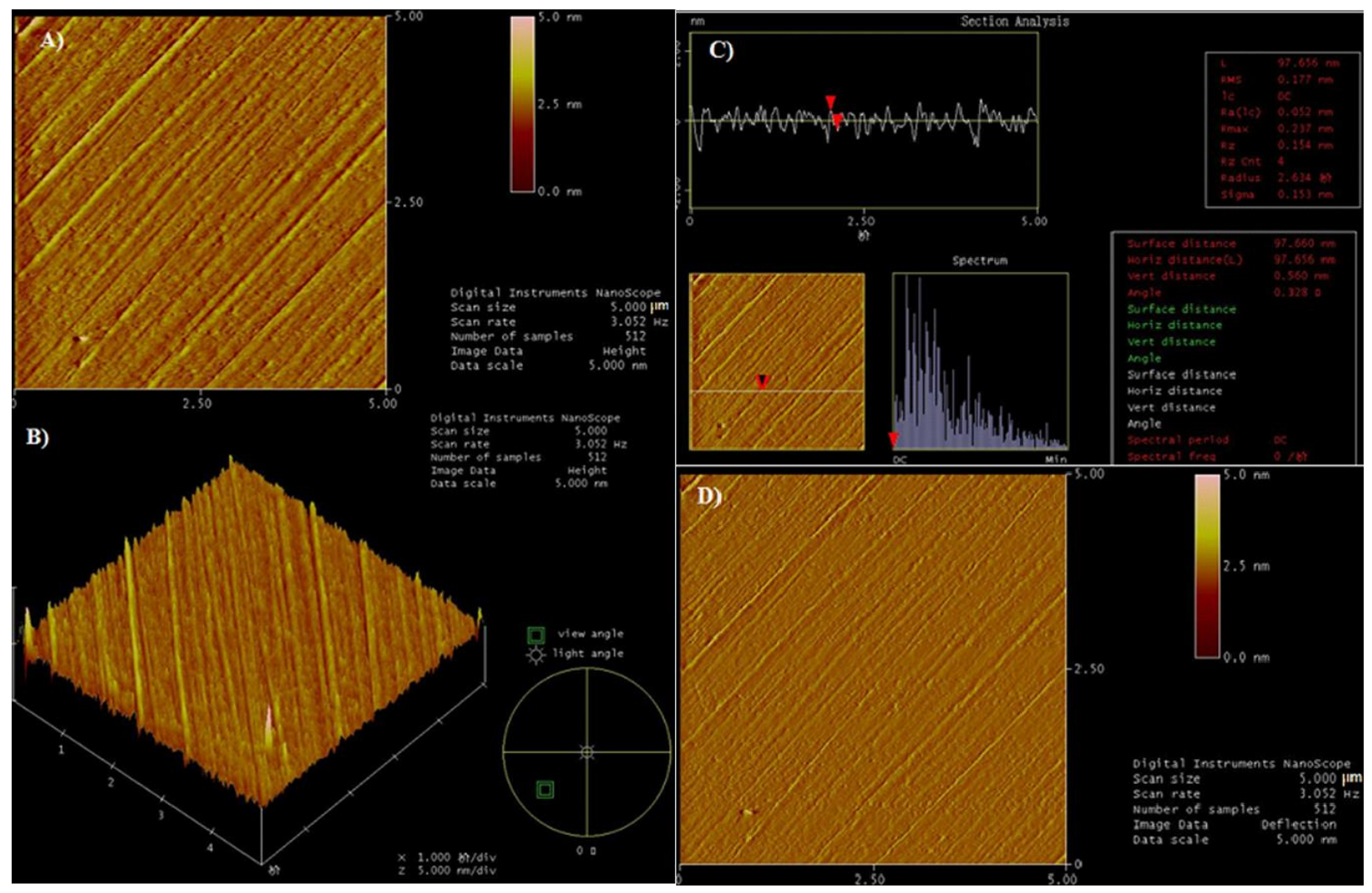

Figure 1 AFM images of bastnaesite surface soaked in water for 30 mins A) the $5 \mu \mathrm{m} \times 5 \boldsymbol{\mu m}$ height image with a data scale of $5 \mathrm{~nm}$; B) the 3-D image; C) the section analysis; D) the deflection image with a data scale of $5 \mathrm{~nm}$. 


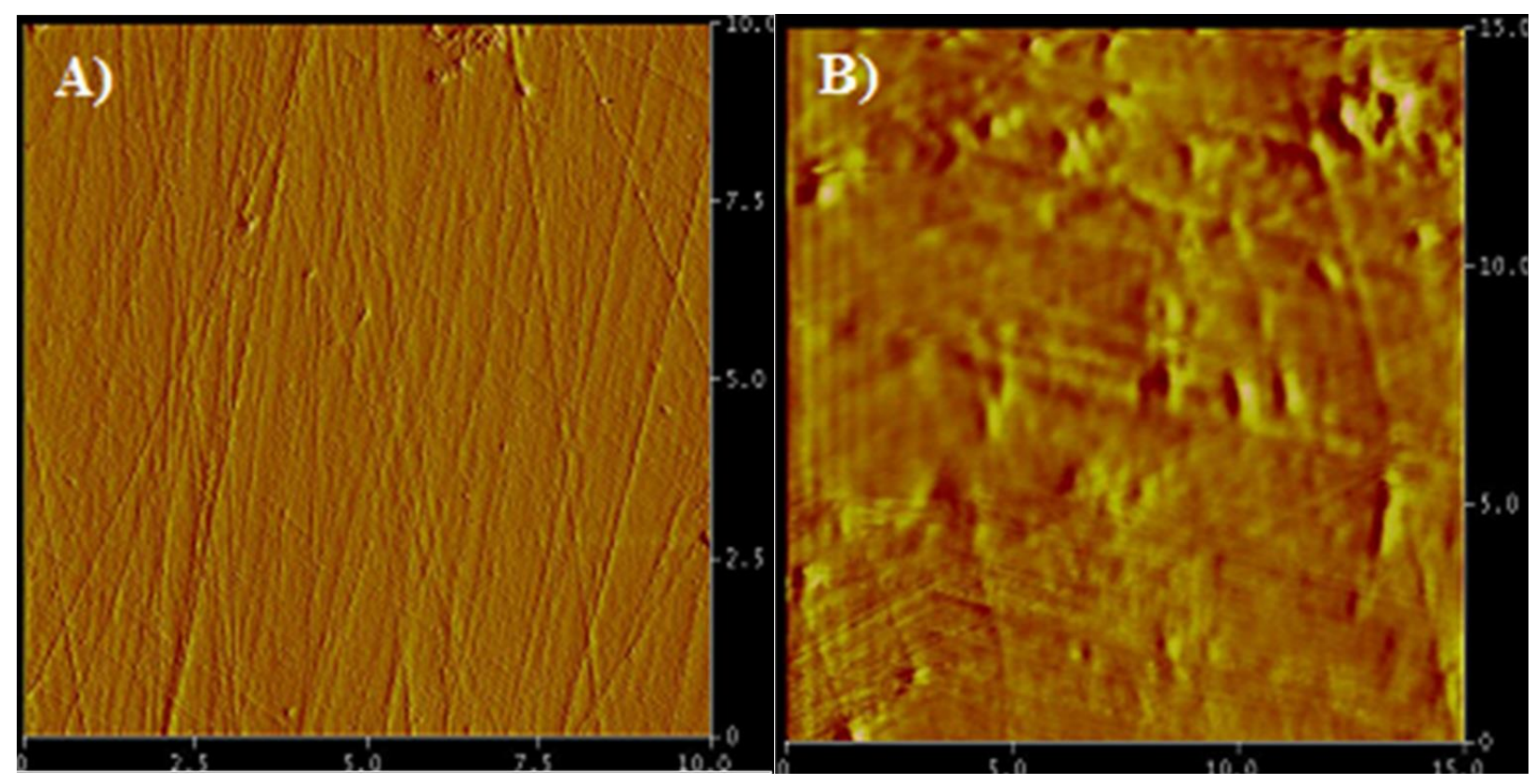

Figure 2 AFM images of bastnaesite soaked in oleic acid solutions at room temperature. A) bare surface soaked in water; B) in $0.02 \mathrm{~g} / \mathrm{L}$ oleic acid for $20 \mathrm{mins}$. 


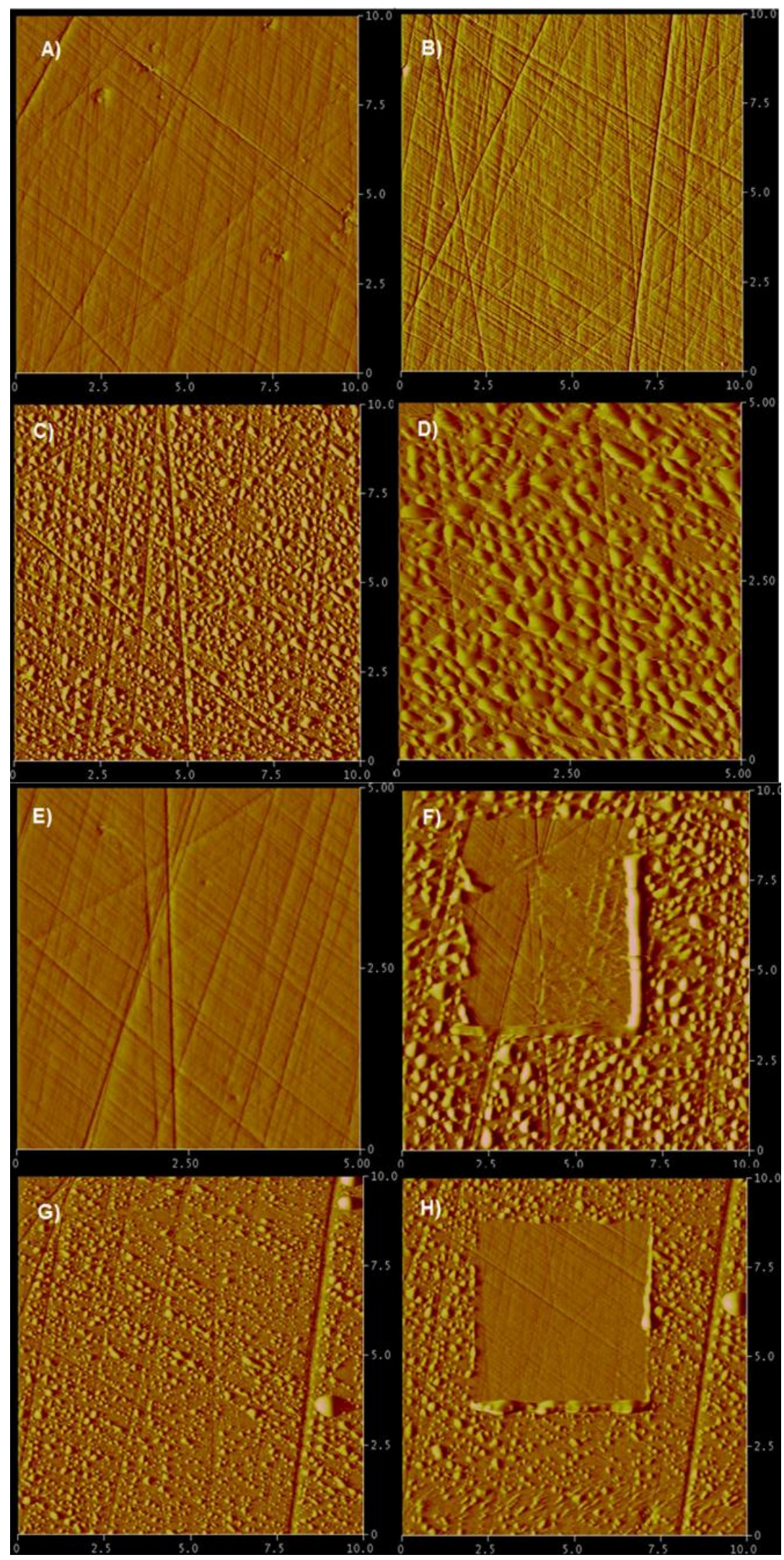

Figure 3. AFM images of bastnaesite soaked in oleic acid solutions at different temperatures. 


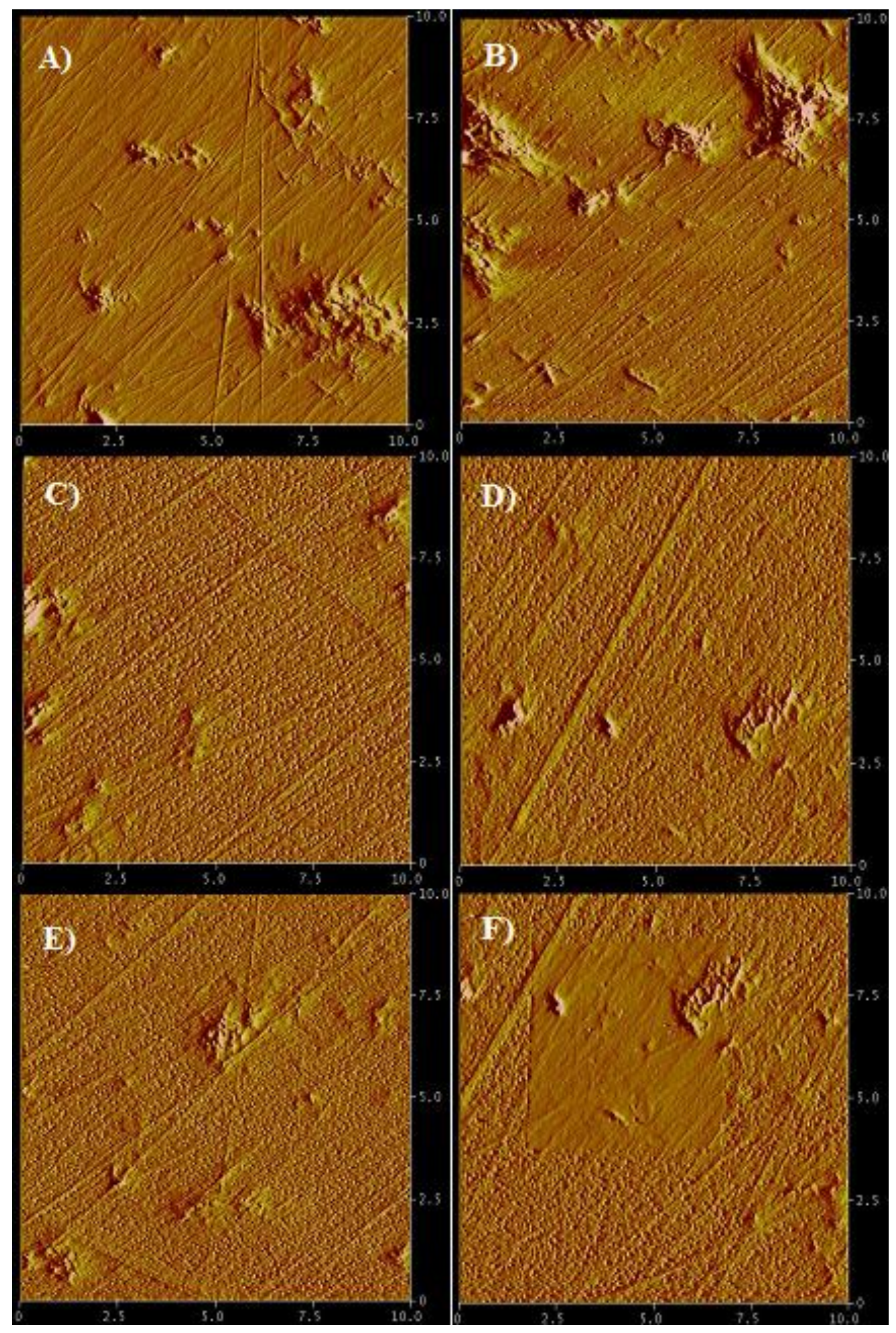

Figure 4 AFM images of bastnaesite soaked in HA solution. 


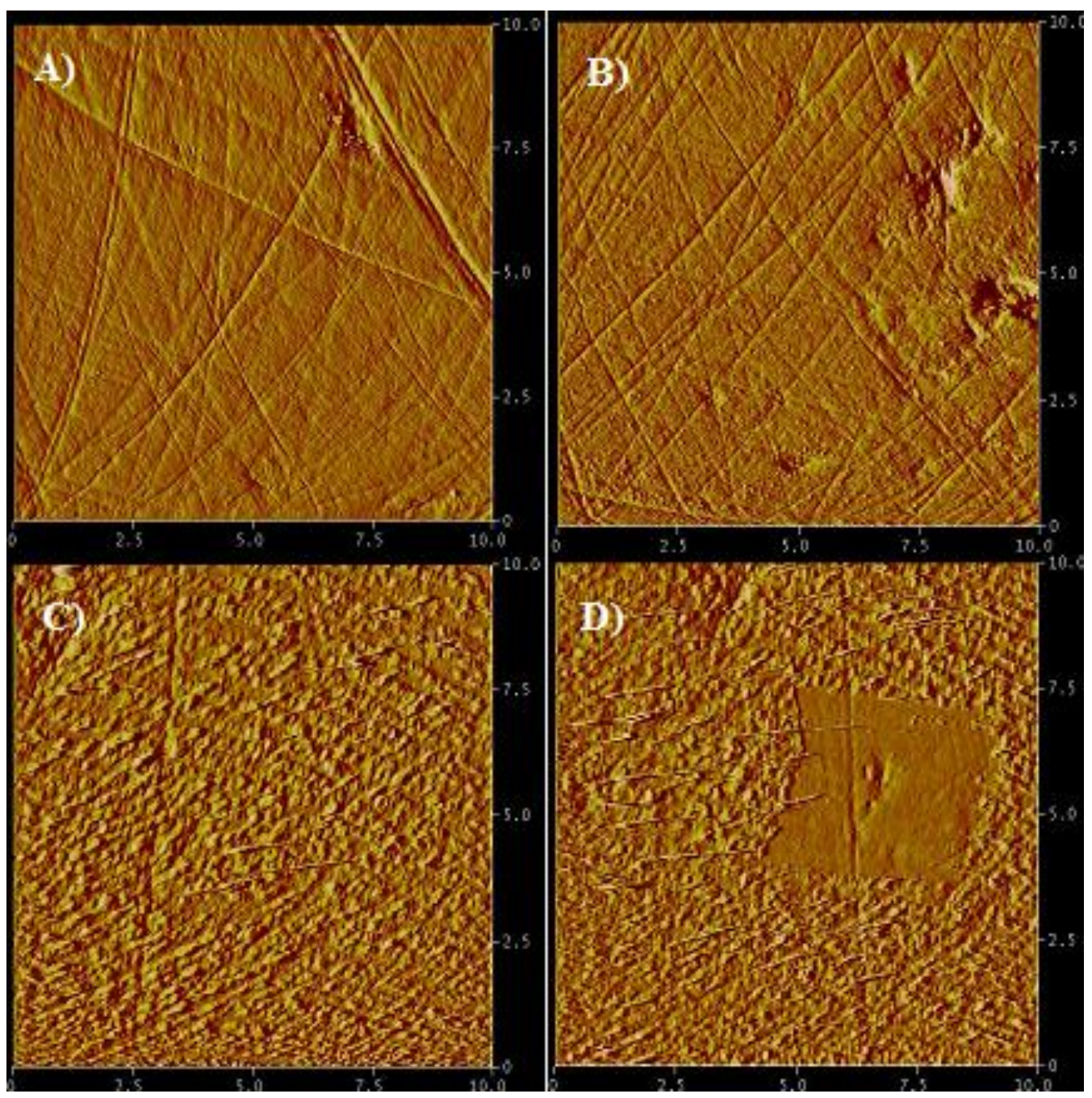

Figure 5 AFM images of bastnaesite soaked in SHA solution. 


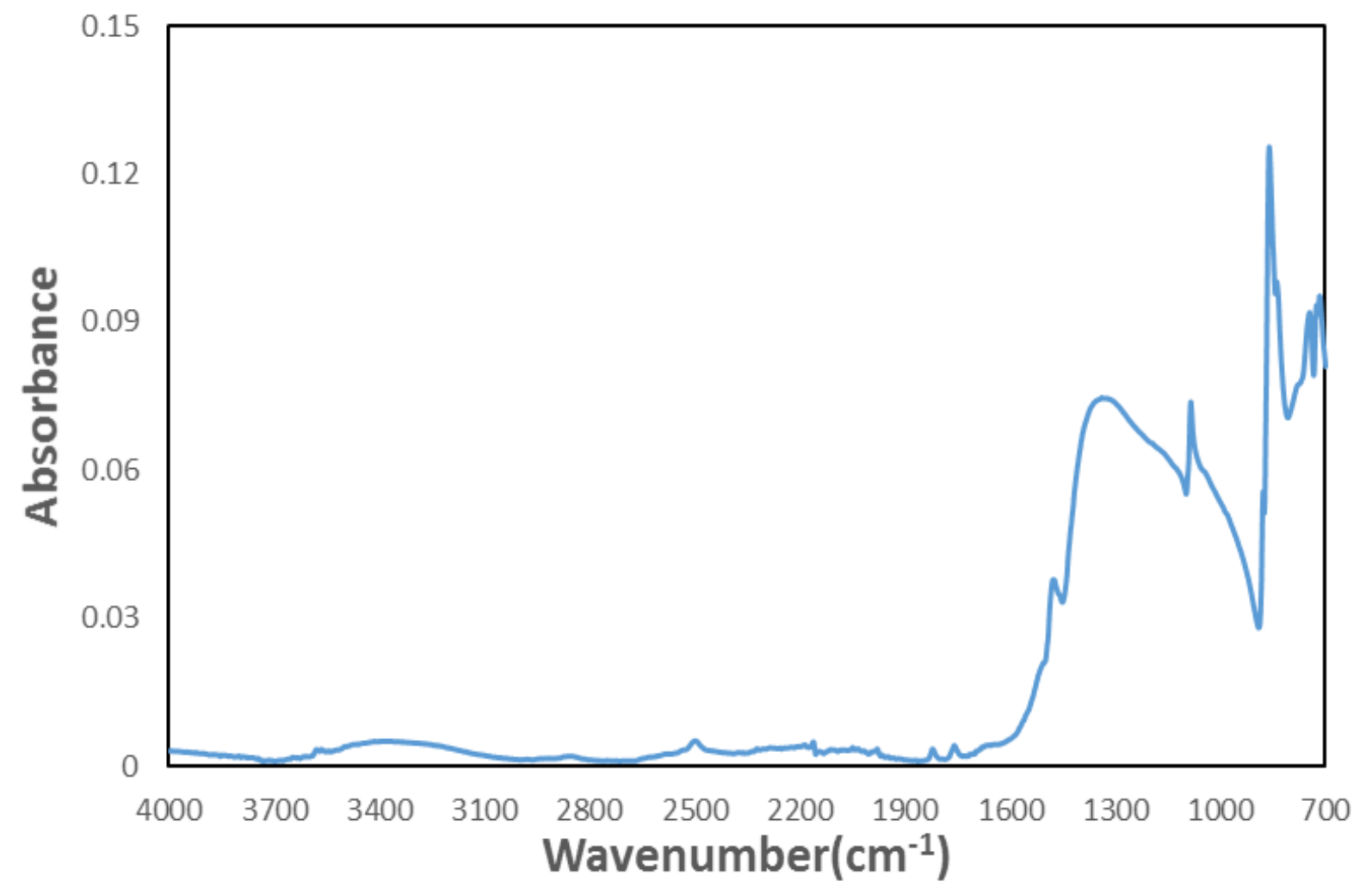

Figure 6. FTIR spectra of pristine bastnaesite surface as studied in this study. 

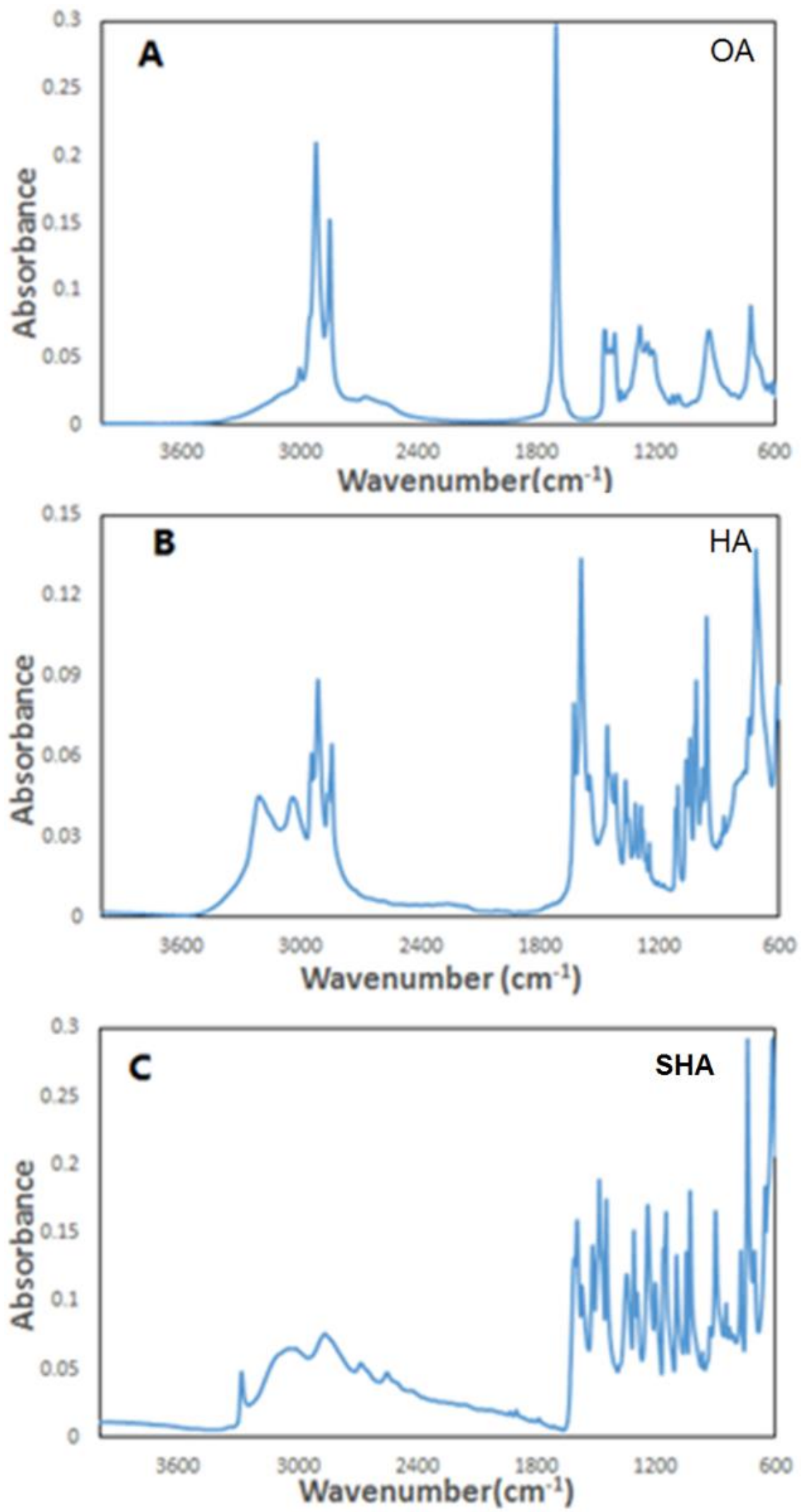

Figure 7 FTIR spectra of chemicals: A) OA; B) HA and C) SHA. 

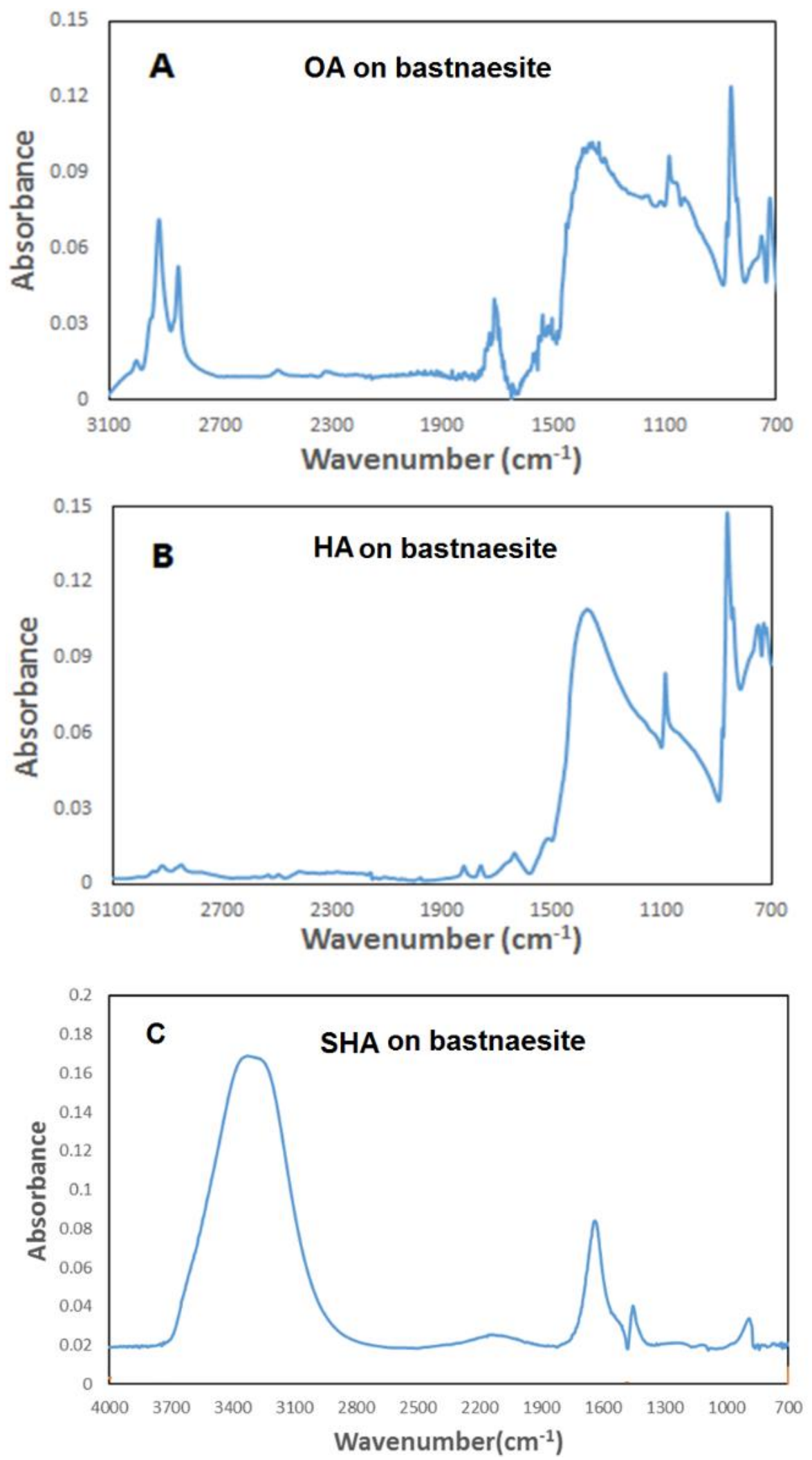

Figure 8. FTIR spectra of bastnaesite surface after being treated with A) $0.2 \mathrm{~g} / \mathrm{L} \mathrm{OA}$; B) $0.2 \mathrm{~g} / \mathrm{L}$ HA and C) $0.4 \mathrm{~g} / \mathrm{L} \mathrm{SHA}$ for 15 minutes. 